\title{
The pancreatic beta cell: an intricate relation between anatomical structure, the signalling mechanism of glucose-induced insulin secretion, the low antioxidative defence, the high vulnerability and sensitivity to diabetic stress
}

\author{
Sigurd Lenzen ${ }^{1}$ D
}

Received: 6 December 2020 / Accepted: 9 March 2021 / Published online: 31 March 2021

(c) The Author(s) 2021

\begin{abstract}
The biosynthesis of insulin takes place in the insulin-producing beta cells that are organized in the form of islets of Langerhans together with a few other islet cell types in the pancreas organ. The signal for glucose-induced insulin secretion is generated in two pathways in the mitochondrial metabolism of the pancreatic beta cells. These pathways are also known as the triggering pathway and the amplifying pathway. Glucokinase, the low-affinity glucose-phosphorylating enzyme in beta cell glycolysis acts as the signal-generating enzyme in this process. ATP ultimately generated is the crucial second messenger in this process. Insulin-producing pancreatic beta cells are badly protected against oxidative stress resulting in a particular vulnerability of this islet cell type due to low expression of $\mathrm{H}_{2} \mathrm{O}_{2}$-inactivating enzymes in various subcellular locations, specifically in the cytosol, mitochondria, peroxisomes and endoplasmic reticulum. This is in contrast to the glucagon-producing alpha cells and other islet cell types in the islets that are well equipped with these $\mathrm{H}_{2} \mathrm{O}_{2}$-inactivating enzymes. On the other hand the membranes of the pancreatic beta cells are well protected against lipid peroxidation and ferroptosis through high level expression of glutathione peroxidase $4(\mathrm{GPx} 4)$ and this again is at variance from the situation in the non-beta cells of the islets with a low expression level of GPx4. The weak antioxidative defence equipment of the pancreatic beta cells, in particular in states of disease, is very dangerous because the resulting particular vulnerability endangers the functionality of the beta cells, making people prone to the development of a diabetic metabolic state.
\end{abstract}

Keywords Pancreatic beta cells · Glucokinase $\cdot$ ATP $\cdot$ Hydrogen peroxide-inactivating enzymes · Glutathione peroxidases · Peroxiredoxins $\cdot$ Catalase $\cdot$ Oxidative stress $\cdot$ Vulnerability of the beta cells

$\begin{array}{ll}\text { Abbreviations } \\ \mathrm{GPx} & \text { Glutathione peroxidase } \\ \mathrm{H}_{2} \mathrm{O}_{2} & \text { Hydrogen peroxide } \\ \mathrm{O}_{2}^{\bullet-} & \text { Superoxide radical } \\ \mathrm{HO}^{\bullet} & \text { Hydroxyl radical } \\ \mathrm{Prx} & \text { Peroxiredoxin } \\ \text { SOD } & \text { Superoxide dismutase }\end{array}$

Sigurd Lenzen

lenzen.sigurd@mh-hannover.de

Institute of Experimental Diabetes Research, Hannover Medical School, 30625 Hannover, Germany

\section{Insulin biosynthesis and secretion}

The peptide hormone insulin (51 amino acids; molecular weight $5.8 \mathrm{kDa}$ ) is of central importance for the regulation of carbohydrate metabolism. Lack of insulin causes severe hyperglycaemia, which results in a life-threatening diabetic metabolic state. It is synthesised in the beta cells of the islets of Langerhans of the pancreas. The physiological regulator of insulin biosynthesis is the blood glucose concentration. An increase in its concentration stimulates insulin biosynthesis. Insulin consists of two peptide chains, the A-chain with 21 amino acids and the B-chain with 30 amino acids. The two chains are linked by two disulfide bridges. A third disulfide bridge within the A-chain is important for stabilising the spatial structure of insulin. A number of genetically modified human insulins with shorter or longer half-lives are nowadays available for the therapy of patients with diabetes. 
Proinsulin, the precursor of insulin, is synthesised via the peptide preproinsulin in the rough endoplasmic reticulum of pancreatic beta cells as a single-stranded polypeptide chain. A- and B-chains of proinsulin are connected by a so-called C-peptide ("connecting peptide"). The A- and $\mathrm{B}$-chains are linked by oxidation of $\mathrm{SH}$ groups via disulfide bridges and thereafter the connecting C-peptide, which connects the two chains, is cut out by proteolysis [1]. Insulin and C-peptide are stored in an equimolar ratio in the insulin secretory granules formed in the Golgi complex until their content is released from the beta cells by exocytosis. During this process, the membrane of the granule and that of the cell surface fuse, so that insulin and C-peptide enter the extracellular space. From there, insulin is transported via the bloodstream to the target organs. No biological function is known for the C-peptide.
The signal for the physiological insulin secretion induced by glucose is generated in the metabolism of glucose [2]. It is ATP (adenosine triphosphate), or more precisely the increase in the ratio of ATP/ADP in the pancreatic beta cells that triggers insulin secretion [2]. Thus, ATP produced in the metabolism of glucose is not only an energy source for the beta cells but also the signal for initiation of insulin secretion. Four biological structures are crucial for the generation of the signal for glucose-induced insulin secretion (Fig. 1):

1. When the blood glucose concentration increases after ingestion of food, the glucose concentration in the extracellular space of the beta cells is raised. The glucose molecules are transported into the cytoplasm of the beta cells by facilitated diffusion by means of a low-affinity glucose transporter (especially the GLUT2) in the

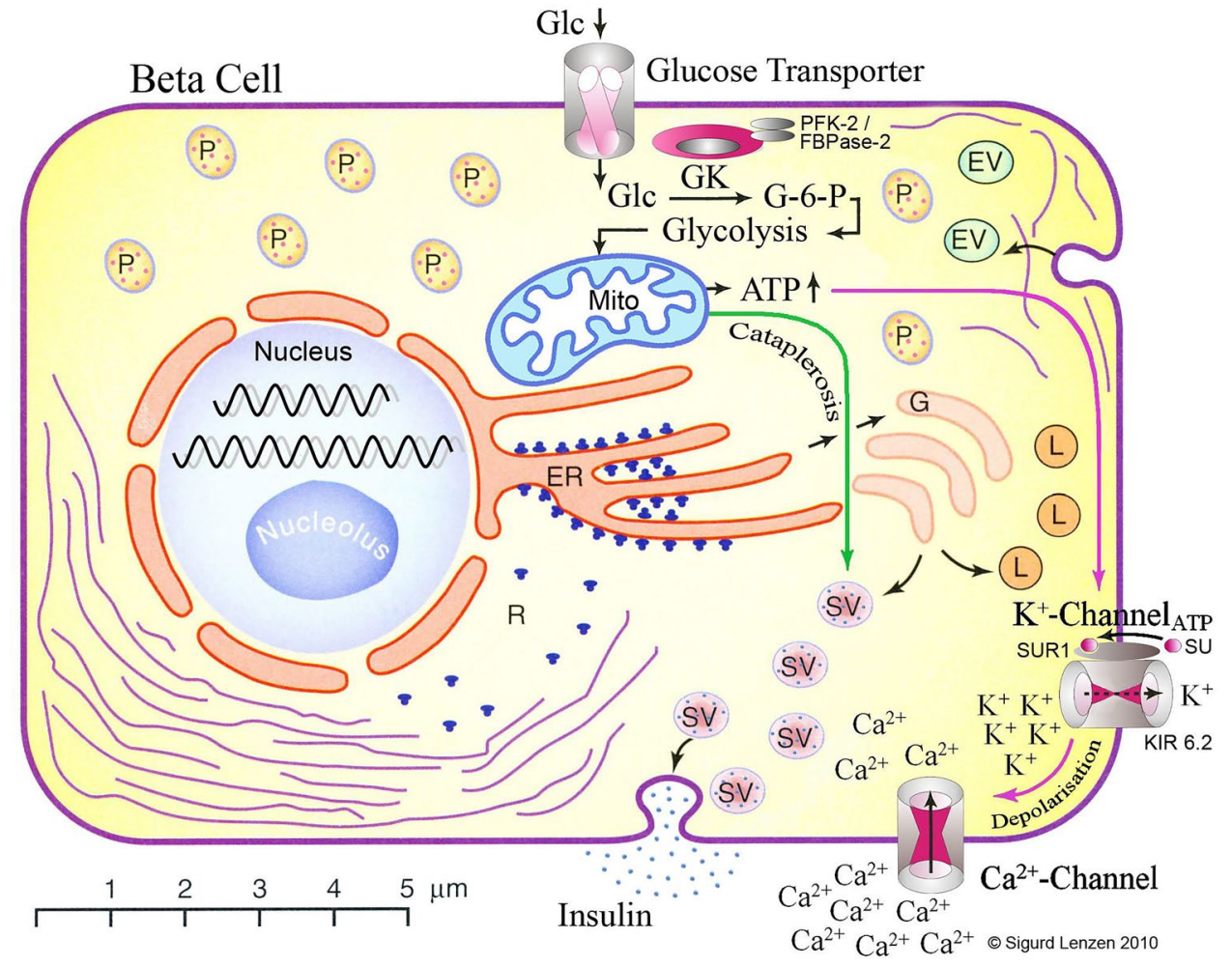

Fig. 1 A scheme of the cellular structures important for physiological regulation of insulin secretion in pancreatic beta cells. Depicted are the nucleus, the mitochondria (Mito), the peroxisomes $(\mathrm{P})$, the lysosomes (L), the endoplasmic reticulum (ER), the Golgi apparatus (G) and the secretory granules (SV). Elevated postprandial blood glucose increases the glucose concentration within beta cells via rapid equilibration through the glucose transporters in the plasma membrane. Glucose is phosphorylated by glucokinase (GK). This leads to the production of glucose-6-phosphate (G6P) and determines the rate of glycolysis. The elevated glycolytic flux and the mitochondrial metabolism stimulate the ATP production. An increase in the cytosolic ATP/ADP ratio induces the closure of ATP-sensitive potassium $\left(\mathrm{K}_{\mathrm{ATP}}\right)$ channels and depolarizes the plasma membrane. This is called the initiating pathway (red arrow). The $\mathrm{K}_{\mathrm{ATP}}$ channel is a com- plex of four pore-forming Kir6.2 subunits and four regulatory SUR1 subunits. The SUR1 subunit can react with blood glucose-lowering sulfonylurea drugs (SU) to initiate insulin secretion. The closure of $\mathrm{K}_{\mathrm{ATP}}$ channels results in the opening of voltage-sensitive $\mathrm{Ca}^{2+}$ channels and leads to $\mathrm{Ca}^{2+}$ influx into the cell. This stimulates exocytosis of insulin-containing secretory granules. The second mechanism enabling glucose-induced insulin secretion potentiation is called the amplifying pathway (green arrow). This mechanism is based on the anaplerosis (providing intermediates of tricarboxylic acid cycle) without involvement of the $\mathrm{K}_{\mathrm{ATP}}$ channel. Many hormones, small peptides and extracellular messengers can also potentiate glucose-induced insulin secretion through binding to their plasma membrane receptors and activation of intracellular signalling cascades, typically G-protein-mediated (not depicted here) 
plasma membrane, so that the intracellular concentration always corresponds approximately to the glucose concentration in the extracellular space (Fig. 1) [2].

2. In addition to high-affinity hexokinase isoenzymes with $K_{\mathrm{m}}$ values in the micromolar concentration range, which are found in all organs, the pancreas (beta cells) is virtually the only organ besides the liver that possesses a low-affinity glucose phosphorylating enzyme, namely the hexokinase IV, better known as glucokinase. In pancreatic beta cells, glucokinase is the signal recognition enzyme responsible for mediating glucose-induced insulin secretion, known as the glucose sensor. By phosphorylating the glucose in the physiological millimolar concentration range (4-8 $\mathrm{mM})$, the glucokinase generates an increased metabolic flow rate, resulting in an increase in the concentration of ATP and a simultaneous decrease in ADP. ATP thus acts as a second messenger in the beta cells (Fig. 1).

3. ATP binds to a specific potassium channel, the ATPsensitive potassium channel in the cell membrane of the pancreatic beta cells, thereby causing depolarisation of the beta cells [2]. This channel protein is associated with a second protein, the so-called sulfonylurea receptor, which is the site of action of the blood sugar-lowering sulfonylureas (Fig. 1) [2].

4. The beta cells have in addition a voltage-dependent calcium channel. As a result of the depolarisation of the beta cells, this channel opens and allows calcium to flow in from the extracellular space. The increase in the free calcium concentration in the cytoplasm of the beta cells is then responsible for triggering glucose-induced insulin secretion by exocytosis [2], which is characterised by a biphasic kinetic profile (Fig. 1).

These four structures together form the apparatus for the recognition of the glucose stimulus and exocytosis of insulin in the beta cells of the islets of Langerhans in the pancreas (Fig. 1) [2]. In healthy people, they ensure that the stored insulin is released as needed when the blood sugar concentration increases after food intake (typically from about 4 to about $8 \mathrm{mM}$ ). Different pathomechanisms are responsible for impaired insulin secretion in type 1 and type 2 diabetes [1-3].

Furthermore, various amino and keto acids, as well as glucose, can increase insulin secretion by means of ATP. In addition, there are other second messengers that can also increase the cytoplasmic calcium concentration and thus increase insulin secretion. For example, for many peptides (e.g. the incretin hormones glucagon-like peptide 1 [GLP1] and gastric inhibitory polypeptide [GIP]), cyclic AMP (cAMP) and in the case of vagal stimulation with acetylcholine inositol trisphosphate are the responsible second messengers. The concentrations of these intracellular second messengers are increased in the beta cell when the respective agonist binds to its plasma membrane receptor. In contrast to glucose, these mechanisms cannot trigger insulin secretion. However, glucose-induced insulin secretion can be increased during food intake and thus optimally adapted to the respective metabolic situation, so that the organism is supplied with insulin as needed.

A second $\mathrm{K}^{+}{ }_{\text {ATP }}$ channel-independent pathway has also been identified [2, 4], called the amplifying pathway of glucose-stimulated insulin secretion. This latter pathway amplifies the signal generated by the triggering pathway through metabolic amplification of the action of increased cytosolic $\mathrm{Ca}^{2+}$ [2]. The amplifying metabolic signals are most likely generated in the tricarboxylic acid cycle [2]. In quantitative terms the amplifying pathway provides at least as much insulin to the organism as the triggering pathway [2].

\section{The islets of Langerhans in the pancreas}

The insulin-producing beta cells as well as the other hormone-producing cells are arranged in the form of endocrine micro-organs, the so-called islets of Langerhans or pancreatic islets. The islets are embedded in the exocrine tissue of the pancreas (total number of islets $0.5-1.5 \times 10^{6}$ ). The average islet has a diameter of 100-200 $\mu \mathrm{m}$ and consists of 500-2000 endocrine cells. The proportion of the endocrine cell mass in the pancreas organ is around $2 \%$.

The islets of Langerhans are composed of different endocrine cell types. The total proportion of insulin-producing beta cells is between $70 \%$ and $80 \%$, the proportion of the glucagon-producing alpha cells with their insulin antagonistic action is between $10 \%$ and $20 \%$, and that of the somatostatin-producing delta cells under $10 \%$. In addition some islets in the pancreatic head contain pancreatic polypeptide cells $(2-3 \%)$. The last two hormones have no crucial function in the organism. In rodents the beta cells are located in the centre of the islet, surrounded by a rim of the non-beta cells (so-called mantle islets), while the non-beta cells are scattered around throughout the islets in-between the beta cells in the human islets.

\section{The sensitivity of pancreatic beta cells to oxidative stress}

The pancreatic beta cell is very sensitive to oxidative stress, explaining its particular vulnerability in states of disease [1]. It is the imbalance between $\mathrm{H}_{2} \mathrm{O}_{2}$ generation and its decomposition that easily causes damage to the beta cells [3].

In virtually all cell types and organs such as liver, kidney and other major organs of the body, the balance between 
$\mathrm{H}_{2} \mathrm{O}_{2}$ generation and decomposition is maintained by a battery of $\mathrm{H}_{2} \mathrm{O}_{2}$-inactivating enzymes [5-8]. They prevent oxidative stress that is an imbalance between the generation of reactive oxygen species and the capacity to detoxify these reactive species. All the protective enzymes generate $\mathrm{H}_{2} \mathrm{O}$ through reduction of $\mathrm{H}_{2} \mathrm{O}_{2}$ and are not inducible. The great number of these decomposing enzymes expressed in virtually all major subcellular compartments is an indication of their importance in providing efficient protection against oxidative stress-mediated cellular toxicity. The effective inactivation systems limit the lifetime and restrict the movements of $\mathrm{H}_{2} \mathrm{O}_{2}$ over large distances and thus provide protection against oxidative stress. This has favourable consequences for the cell: (a) oxidative stress and the resultant cell death are counteracted and (b) localized oxidation of reactive thiol proteins within the cell as the basis for thiol-based cellular signalling is favoured. This restricts $\mathrm{H}_{2} \mathrm{O}_{2}$ distribution in the cell. This is general thinking in the research community [7, 8]. However, it does not apply to the special situation prevailing in the pancreatic beta cell $[1,3,5,6]$. Though the pancreatic beta cell is of crucial importance in the regulation of metabolism, virtually none of the well-known $\mathrm{H}_{2} \mathrm{O}_{2}$-inactivating enzymes is expressed in the beta cells of mice and rats $[1,3]$. This refers specifically to the glutathione peroxidases (GPx) $[5,6,9]$ and the peroxiredoxins (Prx) $[10,11]$ as high-affinity thiol-reactive enzymes, which vigorously reduce $\mathrm{H}_{2} \mathrm{O}_{2}$. In view of the low $\mathrm{H}_{2} \mathrm{O}_{2}$-inactivating capacity, a high level of these proteins is required for efficient inactivation of $\mathrm{H}_{2} \mathrm{O}_{2}$ and local signalling $[7,8]$. However, since the expression levels are rather low or even negligible in the beta cells (Table 1), at variance from the high levels in the non-beta cells of the islets, the enzymes of these families are not able to fulfil a protective role [1].

This refers in particular to Prx4 [11] as well as to GPx7 and GPx8 [9] in the ER and to GPx1 in cytosol and mitochondria [5, 6]. It includes also the lack of expression of the low-affinity and high-capacity $\mathrm{H}_{2} \mathrm{O}_{2}$-inactivating catalase in the peroxisomes [5, 6]. A lot of experimental evidence argues in principle against an incompatibility between a proper antioxidative enzyme equipment and unhampered beta cell function: (a) overexpression of catalase in mitochondria of insulin-secreting cells did not negatively affect glucose-induced insulin secretion [12]; (b) overexpression of Prx4 in the ER of rodent beta cells improved glucoseinduced insulin secretion along with enhanced proinsulin mRNA transcription and increased insulin content [11].

The sources of $\mathrm{H}_{2} \mathrm{O}_{2}$ can be very different. In the peroxisomes and in the ER, $\mathrm{H}_{2} \mathrm{O}_{2}$ is generated directly during beta oxidation of long and very long-chain fatty acids and during protein folding, in particular of proinsulin, respectively [1]. In the mitochondria and in the cytosol the superoxide radical $\left(\mathrm{O}_{2}{ }^{\bullet-}\right)$ is generated initially in the respiratory chain on the level of complexes I and III and by NADPH oxidases, respectively [1]. In a subsequent step $\mathrm{H}_{2} \mathrm{O}_{2}$ is generated through dismutation via MnSOD in the mitochondria and $\mathrm{Cu} / \mathrm{ZnSOD}$ in the cytosol $[1,13]$. Both SOD isoenzymes are expressed plentifully $[5,6]$ so that an instantaneous conversion of the superoxide radical $\left(\mathrm{O}_{2}{ }^{-}\right)$into $\mathrm{H}_{2} \mathrm{O}_{2}$ is guaranteed at any time $[1,14]$. Oxidative stress of any kind is immediately translated into increased levels of $\mathrm{H}_{2} \mathrm{O}_{2}$. While $\mathrm{H}_{2} \mathrm{O}_{2}$ levels in the resting cell are typically in the nanomolar range, they quickly reach concentrations in the micromolar range under conditions of oxidative stress [7,8].

All these are ideal premises that allow a quick build-up of $\mathrm{H}_{2} \mathrm{O}_{2}$ concentrations and thus contribute significantly to the high vulnerability of the pancreatic beta cell under conditions of oxidative stress as they prevail in states of the metabolic derangements during disease development and progression:

(a) Beta cell cytokine toxicity in type 1 diabetes mellitus, caused by increased oxidative stress in the mitochondria [1, 15-17]

(b) Beta cell glucolipotoxicity in type 2 diabetes mellitus, caused by increased oxidative stress in the peroxisomes $[1,18,19]$
Table $1 \quad \mathrm{H}_{2} \mathrm{O}_{2}$-decomposing/ inactivating antioxidative enzyme expression in different locations of the pancreatic beta cell

\begin{tabular}{llll}
\hline Location (subcellular compartment) & $\begin{array}{l}\text { Antioxidative } \\
\text { enzyme }\end{array}$ & Expression level & References \\
\hline Cytosol & GPx1 & Low & {$[1,5,6]$} \\
Mitochondria & GPx1 & Low & {$[1,5,6]$} \\
ER & Prdx4 & Low $^{\mathrm{a}}$ & {$[1,11]$} \\
ER & GPx7 & Absent $^{\mathrm{b}}$ & {$[9]$} \\
ER & GPx8 & Absent & {$[9]$} \\
Peroxisomes & Catalase & Absent & {$[1,5,6]$} \\
Subcellular and cellular membranes & GPx4 & High & {$[22]$} \\
\hline
\end{tabular}

${ }^{a}$ High expression in human beta cells [11]

${ }^{b}$ Expressed only in human beta cells, not in rodent beta cells [9] 
(c) Beta cell glucolipotoxicity in type 2 diabetes mellitus, caused by increased oxidative stress in the ER $[1,9,19]$

(d) Beta cell toxicity in experimental alloxan diabetes by increased oxidative stress in the cytosol [20]

When comparing the gene expression levels of the different $\mathrm{H}_{2} \mathrm{O}_{2}$-decomposing enzymes in rodent and human beta cells, one observation is remarkable. It is the protective antioxidative enzyme equipment of the endoplasmic reticulum (ER) (Table 1). While the ER of the rodent beta cells expresses little Prx 4 and no GPx7, Prdx 4 is highly expressed along with additional expression of GPx7 in the human ER. Thus, human ER is better protected against oxidative stress. This is convincingly documented by the observation that high Prdx 4 expression significantly improved (pro)insulin folding [9], resulting in an improved insulin content and in higher rates of physiological glucose-induced insulin secretion [9].

With respect to a signalling function of $\mathrm{H}_{2} \mathrm{O}_{2}$ in the beta cells by a physiological role through selective thiol group oxidation and a pathophysiological role in the mediation of cellular dysfunction and cell death, the low level of $\mathrm{H}_{2} \mathrm{O}_{2}$-decomposing enzyme expression in the beta cell may favour $\mathrm{H}_{2} \mathrm{O}_{2}$ interactions with enzyme proteins and may provide a larger chance for interaction also with less reactive thiol groups because of (a) a longer lifetime and (b) resulting ability to travel longer distances within a cellular compartment and even into neighbouring compartments through aquaporins $[1,21]$. These aquaporins are water channels in the cellular and subcellular membranes. Thus, all the subcellular compartments in the whole beta cell are the battlefield for the toxic actions of $\mathrm{H}_{2} \mathrm{O}_{2}$ and its products, in particular the most toxic hydroxyl radical $\left(\mathrm{HO}^{\bullet}\right)$, which can be generated at any site of the intracellular space of the beta cell [1] and can induce death-causing damage at multiple sites in all subcellular compartments at the same time. Thus, $\mathrm{H}_{2} \mathrm{O}_{2}$ generation under any pathological condition that can emerge in the beta cell will hit an unprotected highly vulnerable beta cell $[1,3]$.

Our most recent observation that the cellular and subcellular membranes of the beta cells are quite well protected through high level expression of GPx4 in contrast to the non-beta cells in the islets is remarkable. This enzyme is a mild protector against oxidative stress through its capacity to decompose $\mathrm{H}_{2} \mathrm{O}_{2}$ but a strong protector against lipid peroxidation and ferroptosis [23]. Thus ferroptosis in contrast to apoptosis is not a prominent mechanism of beta cell death. This assumption is supported by the fact that $\mathrm{H}_{2} \mathrm{O}_{2}$ generated within the mitochondria suppressed the expression of the antiapoptotic protein Bcl-2, thereby increasing the Bax/ $\mathrm{Bcl}-2$ ratio in favour of the proapoptotic Bax protein [23].

The good protection of the membranes of the beta cell through Gpx4 expression may help to secure a regulated cell death via apoptosis under conditions of pathological stress rather than through uncoordinated cell death via necrosis with its ruptures of all cell membrane structures. This is favourable also because it prevents the release of cell content with inflammatory potential into the extracellular space. The content of the dying cells encapsulated in the apoptotic bodies of the fragmented cells can be removed by macrophages in a proper fashion. As high-affinity thiol proteins, in particular the high-affinity glutathione peroxidases and peroxiredoxins, are not expressed to any significant extent in the beta cells, the $\mathrm{H}_{2} \mathrm{O}_{2}$ lifespan is increased, enabling long distance travelling of $\mathrm{H}_{2} \mathrm{O}_{2}$ and the gain of access to other subcellular compartments via peroxiporins, $\mathrm{H}_{2} \mathrm{O}_{2}$-channelling aquaporins. On this long journey, $\mathrm{H}_{2} \mathrm{O}_{2}$ may have a greater chance to generate the highly damaging hydroxyl radical $\left(\mathrm{HO}^{\bullet}\right)$, in particular in regions where free iron is available. This observation documents that the beta cell is not just a stupid, badly protected cell type.

\section{Conclusion}

A spartan daily diet with limited availability of carbohydrates and fat along with a decent amount of exercise that avoids obesity is compatible under normal circumstances with the weak antioxidative enzyme equipment of the pancreatic beta cell with its low $\mathrm{H}_{2} \mathrm{O}_{2}$-inactivating enzyme capacity. This is documented by the fact that the beta cell under healthy conditions can survive without damage when the beta cell is not particularly challenged. However, the antioxidative defence of the beta cell may be insufficient to cope with the challenges of a modern lifestyle with a westernised diet.

In the human beta cells, the only significant protective element present is a higher expression level of Prx4 and an additional expression of GPx7 in the ER when compared to rodent beta cells (Table 1). This might be an element of better antioxidative protection against the development of beta cell dysfunction and a deterioration of the insulin production and secretory capacity at least in some human individuals to avoid or at least retard the development of a diabetic state.

In states of metabolic derangement such as obesity, the metabolic syndrome, and type 2 diabetes, but also in autoimmune-mediated type 1 diabetes, the pancreatic beta cells get into a state of severe oxidative stress [1] where the weak antioxidative defence is overwhelmed because it is not made to cope with the challenges of excessive oxidative stress.

Through the experimental evidence accumulated during the last decades it has been possible to identify many of the reasons for the extraordinary sensitivity of the pancreatic beta cell towards oxidative stress with the resultant particular vulnerability [3]. However, the question why pancreatic beta cells are so badly 
protected against oxidative stress due to insufficient capacity for $\mathrm{H}_{2} \mathrm{O}_{2}$ decomposition remains a mystery, probably forever.

Incomprehensibility remains also as to why the insulin-producing pancreatic beta cells are so badly protected against oxidative stress-mediated apoptosis, while glucagonproducing alpha cells and the other islet cell types are well protected. It is also unclear why the opposite becomes true, when it comes to the protection of the membranes of the pancreatic beta cells against lipid peroxidation and ferroptosis through high level expression of GPx4, again at variance from the situation in the non-beta cell islet cells with the low expression level of GPx4.

In conclusion, the beta cells in the islets of Langerhans of the pancreas are a critically important cell type which produces and secretes the vitally important peptide hormone insulin in response to increasing glucose concentrations through generation of the second messenger ATP in the mitochondrial metabolism. On the other hand, it remains a mystery why this crucially important cell type is so particularly vulnerable and sensitive towards oxidative stress.

Funding Open Access funding enabled and organized by Projekt DEAL.

Open Access This article is licensed under a Creative Commons Attribution 4.0 International License, which permits use, sharing, adaptation, distribution and reproduction in any medium or format, as long as you give appropriate credit to the original author(s) and the source, provide a link to the Creative Commons licence, and indicate if changes were made. The images or other third party material in this article are included in the article's Creative Commons licence, unless indicated otherwise in a credit line to the material. If material is not included in the article's Creative Commons licence and your intended use is not permitted by statutory regulation or exceeds the permitted use, you will need to obtain permission directly from the copyright holder. To view a copy of this licence, visit http://creativecommons.org/licenses/by/4.0/.

\section{References}

1. Lenzen S (2017) Chemistry and biology of reactive species with special reference to the antioxidative defence status in pancreatic beta-cells. Biochim Biophys Acta Gen Subj 1861:1929-1942

2. Lenzen S (2014) A fresh view of glycolysis and glucokinase regulation: history and current status. J Biol Chem 289:12189-12194

3. Lenzen S (2008) Oxidative stress: the vulnerable beta-cell. Biochem Soc Trans 36:343-347

4. Panten U, Schwanstecher M, Wallasch A, Lenzen S (1988) Glucose both inhibits and stimulates insulin secretion from isolated pancreatic islets exposed to maximally effective concentrations of sulfonylureas. Naunyn Schmiedebergs Arch Pharmacol 338:459-462

5. Lenzen S, Drinkgern J, Tiedge M (1996) Low antioxidant enzyme gene expression in pancreatic islets compared with various other mouse tissues. Free Radic Biol Med 20:463-466

6. Tiedge M, Lortz S, Drinkgern J, Lenzen S (1997) Relation between antioxidant enzyme gene expression and antioxidative defense status of insulin-producing cells. Diabetes 46:1733-1742
7. Sies H (2017) Hydrogen peroxide as a central redox signaling molecule in physiological oxidative stress: oxidative eustress. Redox Biol 11:613-619

8. Winterbourn CC (2020) Hydrogen peroxide reactivity and specificity in thiol-based cell signalling. Biochem Soc Trans 48:745-754

9. Mehmeti I, Lortz S, Avezov E, Jörns A, Lenzen S (2017) ER-resident antioxidative GPx 7 and GPx8 enzyme isoforms protect insulin-secreting INS-1E beta-cells against lipotoxicity by improving the ER antioxidative capacity. Free Radic Biol Med 112:121-130

10. Wolf G, Aumann N, Michalska M et al (2010) Peroxiredoxin III protects pancreatic $\beta$ cells from apoptosis. J Endocrinol 207:163-175

11. Mehmeti I, Lortz S, Elsner M, Lenzen S (2014) Peroxiredoxin 4 improves insulin biosynthesis and glucose-induced insulin secretion in insulin-secreting INS-1E cells. J Biol Chem 289:26904-26913

12. Lortz S, Gurgul-Convey E, Naujok O, Lenzen S (2013) Overexpression of the antioxidant enzyme catalase does not interfere with the glucose responsiveness of insulin-secreting INS-1E cells and rat islets. Diabetologia 56:774-782

13. Winterbourn CC (2020) Biological chemistry of superoxide radicals. ChemTexts 6:7

14. Lortz S, Gurgul-Convey E, Lenzen S, Tiedge M (2005) Importance of mitochondrial superoxide dismutase expression in insulin-producing cells for the toxicity of reactive oxygen species and proinflammatory cytokines. Diabetologia 48:1541-1548

15. Jörns A, Ertekin UG, Arndt T, Terbish T, Wedekind D, Lenzen S (2015) TNF-alpha antibody therapy in combination with the T-cell-specific antibody anti-TCR reverses the diabetic metabolic state in the LEW.1AR1-iddm rat. Diabetes 64:2880-2891

16. Jörns A, Wedekind D, Jähne J, Lenzen S (2020) Pancreas pathology of latent autoimmune diabetes in adults (LADA) in patients and in a LADA rat model compared with type 1 diabetes. Diabetes 69:624-633

17. Jörns A, Ishikawa D, Teraoku H, Yoshimoto T, Wedekind D, Lenzen S (2020) Remission of autoimmune diabetes by anti-TCR combination therapies with anti-IL-17A or/and anti-IL-6 in the IDDM rat model of type 1 diabetes. BMC Med 18:33

18. Gehrmann W, Elsner M, Lenzen S (2010) Role of metabolically generated reactive oxygen species for lipotoxicity in pancreatic beta-cells. Diabetes Obes Metab 12(Suppl 2):149-158

19. Plötz T, von Hanstein AS, Krümmel B, Laporte A, Mehmeti I, Lenzen S (2019) Structure-toxicity relationships of saturated and unsaturated free fatty acids for elucidating the lipotoxic effects in human EndoC-betaH1 beta-cells. Biochim Biophys Acta Mol Basis Dis 1865:165525

20. Lenzen S (2008) The mechanisms of alloxan- and streptozotocininduced diabetes. Diabetologia 51:216-226

21. Bienert GP, Chaumont F (2014) Aquaporin-facilitated transmembrane diffusion of hydrogen peroxide. Biochim Biophys Acta 1840:1596-1604

22. Krümmel B, Plötz T, Jörns A, Lenzen S, Mehmeti I (2021) The central role of glutathione peroxidase 4 in the regulation of ferroptosis and its implications for pro-inflammatory cytokine-mediated beta-cell death. Biochim Biophys Acta Mol Basis Dis. https://doi. org/10.1016/j.bbadis.2021.166114

23. Mehmeti I, Lenzen S, Lortz S (2011) Modulation of Bcl-2-related protein expression in pancreatic beta cells by pro-inflammatory cytokines and its dependence on the antioxidative defense status. Mol Cell Endocrinol 332:88-96

Publisher's Note Springer Nature remains neutral with regard to jurisdictional claims in published maps and institutional affiliations. 